Orissa Journal of Commerce

Vol. 42, Issue 2, April-June 2021

ISSN: 0974-8482

(C) OJC India. All Right Reserved

URL: www.ojcoca.org

DOI: https://doi.org/10.54063/ojc.2021.v42i02.08

\title{
Investigating the Sustainability of Digital Payments in India
}

\author{
Vandana Bhavsar ${ }^{1 *}$ and Pradeepta Kumar Samanta ${ }^{2}$ \\ ${ }^{1}$ Sr. Associate Professor, School of Management, National Institute of Construction Management and Research, Pune, Maharashtra. \\ E-mail: vandanabbhavsar@gmail.com \\ ${ }^{2}$ rr. Associate Professor, School of Management, National Institute of Construction Management and Research, Pune, Maharashtra. \\ E-mail:samanta.pk@gmail.com \\ ${ }^{*}$ Corresponding author
}

To cite this paper

Bhavsar, V., \& Samanta, P.K. (2021). Investigating the Sustainability of Digital Payments in India. Orissa Journal of Commerce. 42(2), 95-108

Keywords

Digital payments, Digital payment infrastructure, Autoregressive distributed lag model, Financial inclusion, Sustainable developmental goals

JEL Classification C320, E010, E420, E510, O330
Abstract: Globally it has been asserted that digital payments and newer financial technologies if provided profitably and responsibly in a structured environment will enable growth and faster achievement of Sustainable Development Goals for a country. In India, although, digital payment transactions have exponentially increased, the demand for cash also has been on rising trend in the recent years. Therefore, the objective of the present study is to examine the factors leading to sustainability of digital payments in India over the period of 2011: Q1-2020: Q4 by using autoregressive distributed lag model. The results show that per capita net national income and economic shocks (demonetisation and pandemic) positively leads to sustainability of digital payment transactions both in real and nominal terms, whereas, financial inclusion plays no role in sustainability of digital payments. Insights from the findings indicate developmental implications towards increasing need for financial inclusion through financial literacy and increasing economic growth through positive shocks to promote digital payments in India.

\section{Introduction}

Sustainable development is the central idea that revolves around integrating short run and long run problems concerning society, economy and environment (Streurer et al. 2005). Financial inclusion is considered as an economic instrument of inclusive growth and sustainable development. The Global Findex Database (2017) highlights the emerging benefits and status of financial inclusion through digital payments. World over, research studies suggest that digitising payments can further enhance the productivity by augmenting the swiftness of payments and lowering the cost of disbursement. This also led to substantial increase in formal savings. But at the same time the successful implementation of digitisation depends heavily on the necessary technological infrastructure; such as stable electricity and mobile networks and financial structure comprising of an efficient payment structure and a competent network connectivity to deliver the payments. People utilising digital payments should be able to deposit or withdraw their cash securely, easily and with certainty at cash-in and cash-out points. 
In order that the benefits from digital financial services are reaped, the governments should execute relevant legislations which safeguards and protects the consumers.

India in the recent years has witnessed exponential growth in the digital payment transactions due to massive drive by the Government of India's "Digital India" programme. With an objective to push Digital Payments and transform India to cash-less economy, great number of policy and actionable measures are undertaken by the Government for its procurement, service offering and disbursements. In India various types of digital payment systems are available. First, most commonly used digital payment systems in India are Credit and Debit cards. Amongst well-known gateways like Visa, Mastercard, etc., National Payment Corporation of India (NPCI) recently initiated Rupay as domestic gateway. However, over the years the usage of debit cards compared to credit card has increased exponentially. Second popular payment systems are National Electronic Funds Transfer (NEFT), Realtime Gross Settlement (RTGS) and Immediate Payment Service (IMPS). NEFT and RTGS are electronically transferred from one bank account to another bank account directly and are cost-efficient. While IMPS allows to electronically transfer fund instantly any time from one bank account to another bank account. Third widely used payment system is Unified Payment Interface (UPI). This was introduced by NPCI in 2016. Through UPI, funds can be transferred through virtual ID without a requirement of bank account. Further, Bharat Interface for Money (BHIM) app was also launched in 2016 by government of India, to facilitate transfer of money from bank accounts using UPI. Another form of BHIM app is connected with Aadhaar card to aid Aadhar pay options. Fourth, the digital wallets like Paytm, Freecharge, Mobikwik and so on are accessible either on computer or mobile phone. In this, wallet is laden through bank account either through debit or credit card or net banking so as to pay to merchants or people. These wallets apart from money transfers also offer different services like shopping, recharge, bill payments etc. Table 1 shows the trend of different payment instruments (in

Table 1: Trends in Different Payment Instruments

\begin{tabular}{lrrr}
\hline \multicolumn{1}{l}{ Item } & \multicolumn{3}{c}{ Value (Rs. Crore) } \\
\cline { 2 - 4 } & $2015-2016$ & $2018-19$ & $2019-20$ \\
\hline Total Digital Payments (1+2+3+4+5) & 92038329 & 163852286 & 162305934 \\
1. Large Value Credit Transfers - RTGS & 82457801 & 135688187 & 131156475 \\
2. Credit Transfers (AePS -Fund Transfers, APBS, ECS & 8901828 & 26097655 & 28572100 \\
$\quad$ Cr, IMPS, NACH Cr, NEFT, UPI) & & & \\
3. Debit Transfers and Direct Debits (BHIM Aadhaar Pay, & 230354 & 656233 & 826036 \\
$\quad$ ECS Dr, NACH Dr., NETC) & & & \\
4. Card Payments (Credit cards, Debit cards) & 399588 & 1196888 & 1535765 \\
5. Prepaid Payment Instruments (wallet, PPI cards, paper vouchers) & 48758 & 213323 & 215558 \\
Other Payment Channels & & & \\
6. $\quad$ Mobile Payments (mobile app based) & 404091 & 2958407 & 5781435 \\
7. Paper-based Instruments (CTS, others) & - & 8246065 & 7824821 \\
\hline
\end{tabular}

Source: Reserve Bank of India (2020) 
value of transaction) in India. As per Reserve Bank of India (RBI) report 2020, the share of digital transactions in the total volume of non-cash retail payments have grown by 97.0 per cent during 201920 from Rs 95.4 per cent in the previous year.

The digital payments industry in India is poised to reach at US $\$ 700$ billion by 2022 in context of value of transactions. Further, this industry is divided by digital payment system classifications and regions. The digital payment system classification includes $\mathrm{m}$-wallets, internet banking, mobile banking, Point of Sale (POS), and others, whereas, the regions comprise of urban and rural regions. However, in terms of share of digital payments, urban areas contribute significantly as compared to their rural counterparts. Figure 1 displays monthly trend of payment system infrastructure in India. The number of POS terminals, Automated Teller Machines (ATMs) and number of Bharat QR codes increased by 38.2 per cent, 3.08 percent and 74.6 percent respectively (RBI report 2020).

There are several rationales for undertaking this investigation. First, in the economic literature, a high proportion of electronic payment transaction is believed to add to the economic development and also increases the competitiveness, as higher use of digital payments accelerate the consumption expenditure in the economy, leading to higher production of goods and services, which ultimately propels economic growth of a country. Second, electronic payments further aid financial inclusion, by introducing formal financial services to those without an access to the formal banking. In order to make country more digitally enabled society and knowledge driven economy, the central government is

Payment System Infrastructure

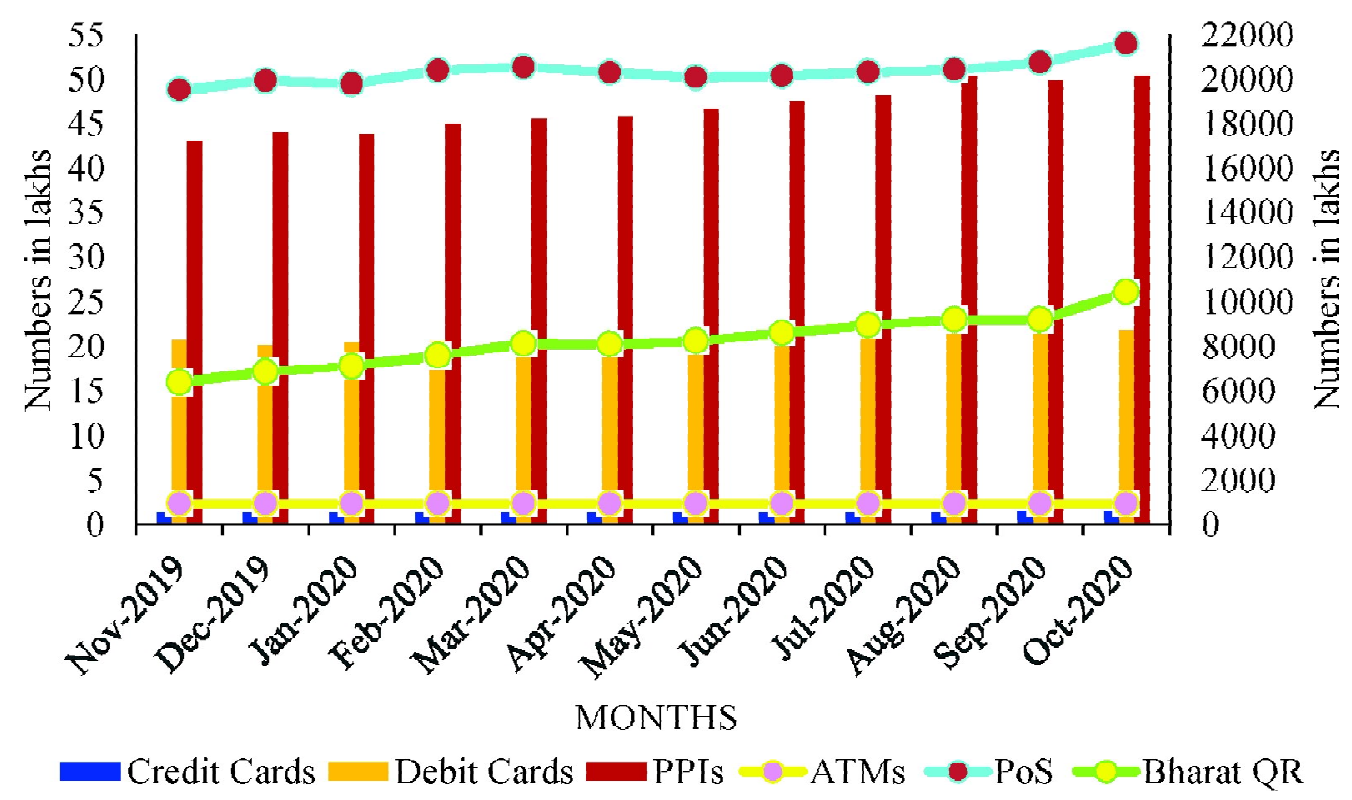

Figure 1: Trends in Payment System Infrastructure

Source: Authors' Compilation from CMIE - Economic Outlook. 
aggressively banking on the Digital India initiative. Through Digital India initiative, government targets to get involved with citizens in the most remote locations in order to involve them into India's growth story. Since technology is a key driver in causing disruptive change, digital tools will empower citizens and prove to be a game-changer. Third, although in India digital payments to GDP ratio did increase significantly post demonetisation, it is evident that the currency in circulation to GDP ratio has also increased during the same period (RBI Bulletin, 2019). Further, international experience shows a slow transition to cashless economy and estimates that the surge in digital payment is temporary. Fourth, the enablers for digital payments in a country are mobile phones and internet, bank accounts, debit and credit cards, underlying digital infrastructure, efforts by the government, growth in the economic activity or growth in per capita income to name the few. Although, country level experiences suggest that these enablers do influence, facilitate and popularise the cashless transactions in a country, their impact on digital payment is not the same both in terms of its usage and popularity. A cross-country study by Bech et al. (2018) indicates that cash still remains the most favoured way of transaction than digital payment transactions because of lower opportunity cost and store of value motive. These divergent experiences indicate ambiguity in the sustainability of digital payments and it thus becomes imperative to examine the factors that lead to the sustainability of digital payments in India.

\section{Review of Literature}

According to D'Silva et al. (2019), Indian economy is predominantly a cash-driven economy. India's approach on digital finance is built upon four components: (i) making available the digital financial infrastructure as a collective commodity; (ii) supporting innovations by making available unrestricted permission to this infrastructure; (iii) giving an equal opportunity to all through the regulatory framework; and (iv) allowing individuals through a data-sharing framework that requires their consent. Further, as per one report, an inclusive digital payments ecosystem is composed of various elements and an empowering environment. The various elements of such an ecosystem contain: i. Digital payment service providers (financial and non-financial operators); ii. A financial infrastructure that consists of payment system; iii. A distribution system (or channels and access points, including agents and direct digital access); iv. An information communication and technology infrastructure as well as energy infrastructure; and v. An efficient user identification system.

With a big push to go digital at all levels, digital modes of payment are gaining popularity. The factors underlying the surge in the usage of digital payments are attractive money-back and userfriendly rewards, quick money transfer digitally, relatively larger transaction security as against credit/ debit cards, lack of transaction costs, general acceptance and minimum risk to name few. Nonetheless, there exists disparities between consumers' expectancy and the satisfaction level which present a threat for sustainability of digital wallets.

Bagla and Sancheti (2018) in their study examines the underlying factors for rising trend of digital wallets in India and investigated sustainability problems encountered by digital wallets as a result of differences between consumers' expectations and their satisfaction level with leading wallet brands like Paytm, Freecharge, Mobikwik and Oxigen. Sikdar and Kumar (2017) have investigated the role of payments banks as the digital payments instruments in achieving the financial inclusion goals. The 
study highlights the advantages of these banks over the formal banking by ensuring the last-mile connectivity in providing benefits to the unbanked and excluded demography.

Gochhwal (2017) studied in detail about the Unified Payment Interface, the technology used and the added benefit that UPI brings in relation to the current digital payment systems. The study tries to decode the technical architecture, transactional processes and security systems of UPI, through which innovative business solutions could be developed. Inclusive finance results in well-being and development of the economy by eradicating or reducing poverty, inequal income distribution and predominance of local bankers. Financial inclusion is thus a multi-dimensional process that concludes once processes like access to and utilisation of financial benefits and banking penetration are completed. Panagariya (2019), in his research paper on digital revolution in India, has asserted that mere availability of technology will not lead individuals to adopt it. The paper has given the instance of a high tax rates scenario wherein parties involved in a transaction are motivated to use cash to make payments and play safe thereby generate a digital record of the transaction by depositing or receiving payments digitally. Thus, the paper underscores the importance of incentives to help permeate the digital revolution across the country.

Dahiya and Kumar (2020) in their study with an aim to examine linkages between financial inclusion and economic growth in India studied three main dimensions of financial inclusion: utilization, penetration and accessibility. The findings of the study reveal a substantial relationship between economic growth and the utilization dimension of financial inclusion in India. Another study tried to determine the financial inclusion in a complex way to understand whether the present apparent important socioeconomic factors of financial inclusion as studied in the literatures are pertinent in a panel data analysis. The econometric evaluation using a panel data analysis of states of India established that income, infrastructure and employment opportunities are possibly the predominant variables of financial inclusion (Raichoudhury, 2020).

Singh and Malik (2019) made an attempt to present the prospects and difficulties arising in the rural banking sector with a particular focus on digitalization. Given the present banking scenario, the paper further analyzes the relevance of digital literacy. Further, to get insight about the perception and behavior of rural consumers regarding these services, the paper also gives an overview of the digital technology and ways adopted by banks in rural India. Arner et al. (2020) asserts that the maximum potential of FinTech to strengthen the Sustainable Development Goals (SDGs) will be achieved with a graded approach to the development of fundamental infrastructure to promote digital financial transformation. The study implies that the feasible remedy to this is to emphasis on four pillars. The first being, creation of digital identity, streamlining opening of bank account and verifying know your customer (e-KYC) systems. This should be through the medium of second pillar of free interactive electronic payments systems. The third pillar includes the use of infrastructure of the first and second pillars to strengthen the electronic supply of public utilities and payments. The last pillar focuses on the structure of digital money markets and systems, which further assists enhanced access to finance and investment. Such an approach of developing digital financial infrastructure depends mainly on the supply of communications' infrastructure. Such an approach offer better opportunities to the countries with higher rate of smart phones penetration and incompetent obsolete financial systems. 
World Bank (2014) in its article presents a dialogue on digital finance and its significance for financial inclusion and financial stability. In emerging and developed economies, through Fintech providers, digital finance has favourable impact on financial inclusion. Further, digital finance is more convenient and valuable to the consumers with low and variable income, since these consumers may incur higher cost for such services from conventional regulated banks. The article further underlines few challenges for financial inclusion and financial stability which the digital finance poses. Ozili (2018) in his study furthers the debate advanced by the World Bank in justification of financial inclusion as useful remedy for alleviating poverty in emerging and poverty stricken countries. The study examines the effect of digital finance for financial inclusion and financial system stability. From theoretical standpoint, the study also highlights the strengths and weaknesses of digital finance, digital financial inclusion and financial inclusion.

According to Draboo (2020), the major stimulus to the measures of financial inclusion has come from Digital India. Different schemes like simplifying universal banking services, reduction of processes related to Permanent Account Number (PAN), unique identification system of Aadhaar, streamlining of taxes through the goods and services tax (GST), etc., have substantially rendered to increase financial inclusion in the country. This study investigates the effect of this schemes and range of activities of Digital India in transforming the conventional manual procedures of utilising government services into digital system. Also, the effect of Digital India on tax (direct and indirect) systems, financial and banking institutions, and the implementation of varied government programmes is also examined.

As concluded by Kim (2014), for the success of digital initiatives, multifaceted procedure is essential, whereby the current digital platforms, infrastructure, human resources, and policy frameworks are enhanced. Of this, human resource is supposed to be leveraged by up-skilling them and encouraging them to participate constructively so as to accomplish the last-mile connectivity of financial institutions. If remedial measures are used to overcome the current problems and interventions, then Digital India has an ability to augment the positive effects of economic development to the poor. Besides, this will lower the expenses for financial institutions and it will also tackle the security issues and accuracy of the data related to financial transactions.

\section{Objectives}

Given the above setting, the intent of this paper is to elucidate the semantics of sustainability of digital payments in India. The main objectives of the study are:

- To study the indicators of sustainability of digital payments.

- To analyse the factors contributing to sustainability of digital payments in India.

\section{Data and Methodology}

\subsection{Data}

In order to formally gauge the sustainability of digital payments in India, the present study for empirical analysis uses the quarterly data from the period 2011-12: Q1-2020-21: Q4. The digital payment transactions as well as mobile banking transactions have been considered both in volume terms (real 
transactions) and in value terms (nominal transactions). The data on the real and nominal digital payments transactions (RDP and NDP), digital payment infrastructure (DI), real and nominal Mobile banking/ payment (RMB and NMB), per capital net national income (PCNNI), growth in the bank accounts (ACT), growth in currency in circulation (CIC) are mainly sourced and assessed from official websites of Reserve Bank of India (RBI) and Centre for Monitoring Indian Economy (CMIE). Additionally, dummy variable (DV) assumes 1 for economic shocks (like demonetisation and current pandemic) and 0 otherwise.

Further as per RBI's payment system indicators, total digital payment is inclusive of large value and retail credit transfers, debit transfers, card payments and Prepaid Payment instruments but excludes mobile payment/banking, whereas digital payment infrastructure is inclusive of ATMs, POS, credit and debit card distributions. Hence in this study, mobile payment/banking is substitute to digital payments.

\subsection{Metbodology}

To achieve the objectives, Autoregressive distributed lag (ARDL) approach to cointegration tests were employed, while for robustness, dynamic ordinary least square (DOLS) method was deployed. The empirical approach viz., unit root and cointegration have been employed to investigate the linkage between digital payments and economic growth in India. Autoregressive distributed lag (ARDL) bounds approach to cointegration and dynamic ordinary least square analysis are directed to test the linkage between the variables. ARDL method developed by Pesaran et al. (2001) was selected compared to other conventional cointegration test primarily because of: i) ARDL could be used to variables regardless of their order of integration, i.e., purely $\mathrm{I}(0)$, purely I(1) or mixed, ii) it gives consistent estimates for small as well as large sample data (Pesaran and Shin, 1995), iii) short-run and long-run estimators could be attained simultaneously. Nevertheless, presence of second order integration makes this test inappropriate; so, it is imperative to test for stationarity of variables. The unit root tests employed to check the stationarity of the variables in the study are Augmented Dicky Fuller (ADF) (1979) and Kwiatkowski-Phillips-Schmidt-Shin (KPSS) (1992). Further, to capture short run and long run dynamics for cointegrating relationship, the bounds test procedure in the unrestricted error correction model is employed as follows:

$$
\begin{aligned}
\Delta R D P_{t}= & \alpha_{0}+\sum_{i=1}^{k} \beta_{i} \Delta P C N N I_{t-1}+\sum_{i=1}^{k} \theta_{i} \Delta D I_{t-1}+\sum_{i=1}^{k} \eta_{i} \Delta R M B_{t-1}+ \\
& \sum_{i=1}^{k} \varphi_{i} \Delta A C T_{t-1}+\sum_{i=1}^{k} \vartheta_{i} \Delta C I C_{t-1}+\sum_{i=1}^{k} \varphi_{i} \Delta D V_{t-1}+\pi_{1} P C N N I_{t-1}+ \\
& \pi_{2} D I_{t-1}+\pi_{3} R M B_{t-1}+\pi_{4} A C T_{t-1}+\pi_{5} C I C_{t-1}+ \\
& \pi_{6} D V_{t-1}+\varepsilon_{t} \\
\Delta N D P_{t}= & \alpha_{0}+\sum_{i=1}^{k} \beta_{i} \Delta P C N N I_{t-1}+\sum_{i=1}^{k} \theta_{i} \Delta D I_{t-1}+\sum_{i=1}^{k} \eta_{i} \Delta N M B_{t-1}+ \\
& \sum_{i=1}^{k} \varphi_{i} \Delta A C T_{t-1}+\sum_{i=1}^{k} \vartheta_{i} \Delta C I C_{t-1}+\sum_{i=1}^{k} \varphi_{i} \Delta D V_{t-1}+\pi_{1} P C N N I_{t-1}+ \\
& \pi_{2} D I_{t-1}+\pi_{3} N M B_{t-1}+\pi_{4} A C T_{t-1}+\pi_{5} C I C_{t-1}+ \\
& \pi_{6} D V_{t-1}+\varepsilon_{t}
\end{aligned}
$$


In order to investigate the long run relationship among the variables, following hypotheses are formulated. The null hypothesis of no cointegration $\left(\mathrm{H}_{0}: \pi_{1}=\pi_{2}=\pi_{3}=\pi_{4}=\pi_{5}=\pi_{6}=0\right)$ is tested against the alternative hypothesis of the existence of cointegration relationship $\left(\mathrm{H}_{\mathrm{A}}: \pi_{1} \neq \pi_{2} \neq \pi_{3} \neq \pi_{4}\right.$ $\neq \pi_{5} \neq \pi_{6} \neq 0$ ). This is based upon the F-test by ordinary least squares (OLS) estimation. This calculated F-statistics value is then compared against Narayan's (2005) critical bounds value especially developed for smaller sample data. Accordingly, in case the calculated F-statistics is higher than the upper critical value, the null hypothesis of no long run cointegration could be rejected i.e., there exists cointegration relationships and vice versa. All the same, if the F-statistics fall between lower and upper critical values the result is inconclusive. Following the confirmation from bounds test about the cointegrating relationship between the variables, the long-run (Equation 3) and short-run (Equation 4) coefficients can be investigated.

$$
\begin{aligned}
& \Delta R D P_{t}=\alpha_{0}+\sum_{j=1}^{k} \delta_{i} \Delta R D P_{t-i}+\sum_{j=1}^{k} \beta_{i} \Delta P C N N I_{t-i}+\sum_{j=1}^{k} \theta_{i} \Delta D I_{t-i}+\sum_{j=1}^{k} \eta_{i} \Delta R M B_{t-i}+ \\
& \sum_{j=1}^{k} \varphi_{i} \Delta A C T_{t-i}+\sum_{j=1}^{k} \zeta_{i} \Delta C I C_{t-i}+\sum_{j=1}^{k} \psi_{i} \Delta D V_{t-i}+\mu_{t} \\
& \Delta R D P_{t}=\alpha_{0}+\sum_{i=1}^{k 1} \alpha_{D P i} \Delta R D P_{t-1}+\sum_{i=1}^{k 2} \alpha_{P C N N I i} \Delta P C N N I_{t-1}+\sum_{i=1}^{k 3} \alpha_{D I i} \Delta D I_{t-1}+ \\
& \sum_{i=1}^{k 4} \alpha_{A C T i} \Delta A C T_{t-1}+\sum_{i=1}^{k 5} \alpha_{M 1 i} \Delta C I C_{t-1}+\sum_{i=1}^{k 6} \alpha_{D V i} \Delta D V_{t-1}+\sum_{i=1}^{k 6} \alpha_{R M B i} \Delta R M B_{t-1}+ \\
& \quad \xi_{1} E C T_{1 t-1}+v_{1 t}
\end{aligned}
$$

where $\mathrm{ECT}_{1}$ refers to error correction term

Likewise, same specification is taken NDP (equation 2) if there is evidence of cointegration. Generally, the ECT $\mathrm{t}_{\mathrm{t}-1}$ should be negative and between 0 to 1 . The $\mathrm{ECT}_{\mathrm{t}-1}$ displays the speed of the adjustment to converge back to its long-run equilibrium. For robustness to ARDL estimates, dynamic ordinary least square method (DOLS) of Stock and Watson (1983) is used. Endogeneity is taken care

Table 2: Unit Root Tests

\begin{tabular}{lcccc}
\hline Variables & \multicolumn{2}{c}{ ADF } & \multicolumn{3}{c}{ KPSS } \\
\cline { 2 - 5 } & Levels & Differenced & Levels & Differenced \\
\hline RDP & -0.10 & $-4.72^{*}$ & 0.70 & $0.19^{*}$ \\
NDP & -1.50 & $-4.53^{*}$ & 0.55 & $0.20^{*}$ \\
DI & -0.46 & $-4.13^{*}$ & 0.71 & $0.19^{*}$ \\
PCNNI & $-3.59^{*}$ & - & 0.68 & $0.32^{*}$ \\
RMB & 1.74 & $-3.45^{* *}$ & 0.73 & $0.31^{* *}$ \\
NMB & -1.76 & $-4.12^{*}$ & $0.65^{* * *}$ & $0.45^{* *}$ \\
CIC & $-7.30^{*}$ & - & $0.35^{* *}$ & - \\
ACT & $-5.33^{*}$ & - & $0.25^{*}$ & - \\
\hline
\end{tabular}

Notes: $\quad$ Eviews 9 used for estimations.

*significant at $1 \%,{ }^{* *}$ significant at $5 \%,{ }^{* * *}$ significant at $10 \%$.

Source: Authors' Calculation 
Investigating the Sustainability of Digital Payments in India

in DOLS by adding the leads and lags. DOLS is easy to compute and outperforms and reduces bias better than fully modified least square (FMOLS), according to Kao and Chiang (2000). The analytical results from these methodologies would throw light on adoption of policies that foster an integrated and harmonised digital payment and also to improve the sustainability of digital payments in the country.

\section{Findings and Discussions}

To achieve the objective of the study, firstly, to ascertain the order of integration of all variables, the unit root test for stationarity of all variables is determined using ADF test and KPSS tests. Table 2 reports the unit root tests carried out on all variables. The test regression includes a constant for the levels and for the first differences of the variables. It is apparent from the outcomes that all series are either stationary for ADF and KPSS at levels or after first difference they are stationary. Hence, these variables are of mix order of integration.

Second step is to test whether there exists cointegration between the variables. For this, equations (1) and (2) are estimated to generate the value of F-statistics and reported in table 3. As stated previously, if $\mathrm{F}$ value is higher than the upper bound critical values, the null hypothesis of no long-run cointegration is rejected. The results in table 3 indicate that the computed F-statistics is more than the upper bound critical value obtained from Table Case II in Narayan (2005). This reflects that null hypothesis is rejected, implying that digital payments and factors influencing the digital payment usage have long-

Table 3: ARDL Bounds Test for Cointegration

\begin{tabular}{|c|c|c|c|c|c|c|}
\hline \multicolumn{4}{|c|}{ Test Statistic } & F-statistic Value & \multirow{2}{*}{$\frac{K}{6}$} & Lags $^{\#}$ \\
\hline F(RDP | PCNNI, DI, & ACT, & RMB, & CIC, DV) & $6.76^{*}$ & & 1 \\
\hline F(NDP $\mid$ PCNNI, DI, & ACT, & NMB, & CIC, DV) & $4.63^{* *}$ & 6 & 2 \\
\hline \multicolumn{7}{|c|}{ Critical Value Bounds (Narayan, 2005) } \\
\hline \multicolumn{4}{|c|}{ Significance level } & IO Bound & & I1 Bound \\
\hline & & & & \multicolumn{3}{|c|}{$\mathrm{n}=39$} \\
\hline \multicolumn{3}{|c|}{$10 \%$} & & 2.224 & \multicolumn{2}{|r|}{3.339} \\
\hline \multicolumn{3}{|c|}{$5 \%$} & & 2.641 & \multicolumn{2}{|r|}{3.881} \\
\hline \multirow{2}{*}{\multicolumn{3}{|c|}{$1 \%$}} & & 3.686 & & 5.184 \\
\hline & & & & \multicolumn{3}{|c|}{$\mathrm{n}=38$} \\
\hline \multicolumn{3}{|c|}{$10 \%$} & & 2.233 & \multicolumn{2}{|r|}{3.354} \\
\hline \multicolumn{3}{|c|}{$5 \%$} & & 2.663 & \multicolumn{2}{|r|}{3.893} \\
\hline \multicolumn{3}{|c|}{$1 \%$} & & 3.621 & \multicolumn{2}{|r|}{5.148} \\
\hline
\end{tabular}

Notes: Eviews 9 used for estimations.

*significant at $1 \%,{ }^{* *}$ significant at $5 \%,{ }^{* * *}$ significant at $10 \%$.

\#According to lag order selection criterion

Source: Authors' Calculation

Orissa Journal of Commerce, 42(2) (C) 2021 
run cointegrating relationship. Alternatively, this implies that the variables form stable long-run relationships amongst each other. This also indicates that there may be disequilibrium among the variables in short run, but in the long run there is equilibrium among the variables.

Once the long-run cointegrating relationship between the variables is established, equations (1) and (2) are estimated using ARDL specification. DOLS is also employed to test the robustness of long-run estimates obtained from ARDL. The findings attained from ARDL and DOLS estimations of the equations (1) and (2) are reported in table 4. It is clear from the long-run ARDL estimates, that the per capita net national income is found to have highest impact on both real and nominal digital payments followed by the economic shocks (dummy variable). Both the variables are positive and significant. This indicates that with increase in the level of income, the probability of using digital payment increases. The per capita net national income result corroborates with findings of Davies et al. (2016), Bech et al. (2018) and Stavins, (2001).

Table 4: ARDL Long Run Estimates

\begin{tabular}{|c|c|c|c|c|}
\hline \multirow[t]{3}{*}{ Variables } & \multicolumn{2}{|c|}{$\begin{array}{l}\text { Autoregressive Distributed lag } \\
\text { model (ARDL) }\end{array}$} & \multicolumn{2}{|c|}{$\begin{array}{l}\text { Dynamic ordinary least square } \\
\text { method (DOLS) }\end{array}$} \\
\hline & \multicolumn{2}{|c|}{ Dependent variable } & \multicolumn{2}{|c|}{ Dependent variable } \\
\hline & RDP (Volume) & NDP (Value) & RDP (Volume) & NDP (Value) \\
\hline DI & 0.23 & $-0.87^{* *}$ & -0.05 & $-0.86^{*}$ \\
\hline PCNNI & $4.74^{*}$ & $9.79^{*}$ & $3.88^{*}$ & $8.35^{*}$ \\
\hline RMB (Volume) & -0.03 & - & 0.02 & - \\
\hline NMB (Value) & - & $-0.31^{*}$ & - & $-0.30^{*}$ \\
\hline $\mathrm{CIC}$ & $0.002^{* * *}$ & $0.03^{* * *}$ & $0.004^{*}$ & $0.01^{* *}$ \\
\hline ACT & 0.005 & $0.13^{* *}$ & 0.001 & $0.09^{*}$ \\
\hline DV & $0.32^{*}$ & $2.10^{* * * *}$ & $0.19^{* * *}$ & $1.84^{* *}$ \\
\hline $\mathrm{C}$ & $-35.16^{*}$ & $-91.65^{*}$ & $-34.05^{*}$ & $-87.65^{*}$ \\
\hline
\end{tabular}

Note: $\quad$ Selected model of RDP $(1,0,0,0,0,0,0)$ and NDP $(1,2,2,2,2,2,2)$ based on Schwarz criterion (SIC). ${ }^{*}$ significant at $1 \%,{ }^{* *}$ significant at $5 \%,{ }^{* * *}$ significant at $10 \%$

Source: Authors' Calculation

Further, according to Mehta et al. (2016) and also as per RBI (2019), as a result of demonetisation, India experienced a transition from cash to digital cash. Similarly, the Covid-19 pandemic also led to increase in usage of digital payments mainly due to concerns about viral transmission from cash. Interestingly, growth in currency in circulation (M1), though is significant has the least impact both on real and nominal digital payments. This indicates that India still has bias for cash payments mainly because people want to keep some money on hand for contingency purposes. Mobile banking both in real and nominal terms in long-run has negative impact on digital payments (real and nominal) signifying a substitution effect. In other words, an increase in mobile payments/banking means less 
use of cards and other digital payment instruments. Additionally, the long-run coefficient estimates of digital infrastructure though positive does not have impact on real digital payments whereas, it has negative and significant impact on nominal digital payments. This result is in line with the findings of Confederation of Indian Industry's (CII) report (2016), which concludes that the digital infrastructure in India is most suitable for mobile and online payments than for digital instruments like (cards usage at POS, ATMs, etc.), and hence mobile banking/payment is substitute of digital payment instruments.

Last but not the least is the growth in bank accounts, which does not have any impact on the real growth of digital payments, however, it has positive impact on nominal growth of digital payments in the country. This indicates that just opening of bank account will not lead to more adoption or usage of digital payment instruments. According to Mukhopadhyay (2016), there exists strong positive relationship between receiving payments in the accounts and usage of digital payments. In India, despite government's efforts to open accounts under Pradhan Mantri Jan Dhan Yojna (PMJDY) to achieve financial inclusion objective, quarter of these accounts have zero-balance or lie dormant. There is thus no motivation to use digital payments.

Overall, the results indicate that in the long-run, in real terms it is only the income and economic shocks which may lead to the sustainability of the digital payments in the country, though in nominal terms apart from these two factors, growth in the bank accounts may also lead to sustainable digital

Table 5: Short Run Error Correction Model

\begin{tabular}{lcc}
\hline Variables & \multicolumn{2}{c}{ Dependent Variable } \\
\cline { 2 - 3 } & RDP (Volume) & NDP (Value) \\
\hline DI & 0.08 & -0.80 \\
PCNNI & $2.73^{*}$ & $5.69^{* *}$ \\
RMB (Volume) & -0.03 & - \\
NMB (Value) & - & -0.02 \\
CIC & $0.002^{* * *}$ & $0.005^{* *}$ \\
ACT & 0.003 & $0.04^{*}$ \\
DV & $0.18^{* *}$ & $0.28^{* * *}$ \\
ECT (-1) & $-0.48^{* *}$ & $-0.63^{*}$ \\
Model diagnostics & & \\
F-statistics & $8.76^{* *}$ & $20.71^{*}$ \\
R-squared & 0.95 & 0.96 \\
Adj. R-squared & 0.91 & 0.92 \\
DW statistics & 1.97 & 1.98 \\
Autocorrelation test & 0.73 & 0.98 \\
Heteroscedasticity test & 1.51 & 0.76 \\
\hline
\end{tabular}

Notes: ${ }^{*}$ significant at $1 \%,{ }^{* *}$ significant at $5 \%,{ }^{* * *}$ significant at $10 \%$

Source: Authors'Calculation 
payments. The DOLS estimation is to greater extent in line with ARDL estimates. Lastly, subsequent to long-run coefficient estimation, short-run error correction model using equations (1) and (2) is estimated and this is supposed to complement long-run ARDL cointegration results.

Table 5 presents results of the short-run ARDL model. The short run results are to a greater extent in accordance with the long-run estimates except for digital infrastructure which is neither significant for real nor for nominal digital payments. Further, the coefficient of $\mathrm{ECT}_{\mathrm{t}-1}$ for RDP and NDP is negative and significant at 5\% and 1\% respectively. The disequilibrium in the short run is adjusted in the long run at a rate of $48 \%$ for RDP and at a rate of $63 \%$ for NDP in the subsequent period. Additionally, the coefficient of determination $\left(\mathrm{R}^{2}\right)$ is between $0.95-0.96$. The estimated shortrun coefficients were exposed to diagnostics test for reliability under Lagrange multiplier (LM) tests. The LM test results indicates that at 5\% level of significance, there is no issue of serial correlation and Heteroscedasticity.

In real terms, as is shown by error correction estimates it follows that the enablers of digital payment slowly converge to long-run equilibrium, whereas, in nominal terms the enablers of digital payment speedily converge to long-run equilibrium. It is hence deduced that in India, the substitution effect of currency in circulation on digital payment is lesser as compared to the stable positive income effect, suggesting that the digital transactions are increasing swiftly.

\section{Conclusion}

In this study, an attempt is made to understand whether the digital payments are sustainable in India by empirically investigating the factors contributing to it. This study tries to examine the factors leading to sustainability of digital payments over the period of 2011-12: Q1-2020-21: Q4. To explore this, the study uses ARDL bounds test to cointegration along with DOLS. The results indicate that in long run per capita net national income and economic shocks (demonetisation and pandemic) both emerge as main factors leading to sustainability of digital payments in real and nominal terms. Mobile banking/payments may not increase the usage of digital payments like cards etc. indicating that it is a substitute of digital payments. Also, digital infrastructure is not found to be an important factor for sustainability of digital payments. Lastly, financial inclusion as proxied by the growth in bank accounts not necessarily leads to sustainability of digital payments.

The payment system in India is moving from issuance stage to acceptance stage. The usage of digital payments basically depends on demand side factors like strong demand for digital payments and supply side factors like resilient digital infrastructure, growth in bank accounts, etc. The digital infrastructure is still low and so is the number of digital transactions, whereas the mobile transactions are rapidly increasing. Hence to increase the acceptance of digital payments, firstly, financial literacy is very important. People must be made aware of the benefits and risks of digital payments and should also be educated about operating their bank accounts. Secondly, all government services, fees, utilities, tolls etc. should have digital payment options. Thirdly, allowing to withdraw small amount of cash from POS/QR. The implication is that mere availability of technology neither makes individual adopt to it nor is it a substitute for financial inclusion. There has to be rigorous efforts both by the government and central bank to make digital payments a divine experience. 
Paucity of usage of various instruments of digital payments before 2011 and lack of availability of mobile banking data has influenced the data period from 2011-12: Q1-2020-21: Q4. Further research on linkages between the consumption pattern of households, usage of various instruments of digital payment and mobile banking can be undertaken to gauge the sustainability of digital payments.

\section{References}

Arner, D. W., Buckley, R. P., \& Zetzsche, R. V. (2020). Sustainability, FinTech and Financial Inclusion. European Business Organization Law Review, 21, 7-35. https://doi.org/10.1007/s40804-020-00183-y.

Asli, D-K., Klapper, L., Dorothe, S. Saniya, A. \& Jake, H. (2018). The Global Findex Database 2017: measuring financial inclusion and the fintech revolution. Washington, DC: World Bank. https:// openknowledge.worldbank.org/handle/10986/29510.

Bagla, R. K., \& Sancheti, V. (2018). Gaps in customer satisfaction with digital wallets: challenge for sustainability. Journal of Management Development, 37(6), 442-451. https://doi.org/10.1108/JMD-04-2017-0144.

Bech, M. L., Faruqui, U., Ougaard, F., \& Picillo, C. (2018). Payments are a-changing but cash still rules. BIS Quarterly Review. https://www.bis.org/publ/qtrpdf/r_qt1803g.htm.

Chaudhari, D. R. Dhal, S., \& Adki, S. M. (2019). Payment systems innovation and currency demand in India: some applied perspectives. Reserve Bank of India Occasional Papers, 40(2), 33-63, New Delhi.

CMIE - Economic Outlook. Data on payment system infrastructure, Nov. 2019 to January 2021 retrieved from https: / / economicoutlook.cmie.com $/ \mathrm{kommon} / \mathrm{bin} / \mathrm{sr} \cdot \mathrm{php}$ ?kall=wreport\&tabcode $=$ 001021010020000000\&oporder $=2$ (accessed 28th February 2021).

Confederation of Indian Industry (2016). e-Commerece in India: a game changer. https://www2.deloitte.com/ content/dam/Deloitte/in/Documents/technology-media-telecommunications/in-tmt-e-commerce-in-indianoexp.pdf.

D’Silva, D., Filková, Z., Packer, F., \& Tiwari, S. (2019). The design of digital financial infrastructure: lessons from India. BIS Papers No. 106. https://www.bis.org/publ/bppdf/bispap106.htm.

Dahiya, S., \& Kumar M. (2020). Linkage between financial inclusion and economic growth: an empirical study of the emerging Indian economy. Vision, 24(2), 184-193.

Data on digital payment indicators accessed from https://dbie.rbi.org.in/DBIE/dbie.rbi?site=statistics.

Data on per capita net national income accessed from https://economicoutlook.cmie.com/kommon/bin/ st.php?kall $=$ wreport\&tabcode $=001001008014000000 \&$ oporder $=0$.

Davies, C., Doyle, M-A., Fisher, C., \& Nightingale, S. (2016). The future of cash. RBA Bulletin, 43-52.

Dickey, D.A., \& Fuller, W.A. (1979). Distribution of the estimators for autoregressive time series with a unit root. Journal of the American Statistical Association, 74(366), 427-431. DOI: 10.2307/2286348.

Draboo, S. (2020). Financial inclusion and digital India: A critical Assessment. Economic \& Political Weekly, 55(17).

Gochhwal, R. (2017). Unified payment interface-an advancement in payment systems. American Journal of Industrial and Business Management, 7, 1174-1191.

Herwadkar, S., Verma, R., \& Bilantu, P. (2019). Drivers of digital payments: a cross country study. Reserve Bank of India Bulletin, New Delhi.

Kao, C., \& Chiang, M. H. (2000). On the estimation and inference of a cointegrated regression in panel data. In: Baltagi, B., ed. Nonstationary Panels, Panel Cointegration, and Dynamic Panels (Advances in Econometrics, Vol. 15), Amsterdam: JAI Press, pp. 161-178. 
Kim, J. Y. (2014). Digital Financial Inclusion. The World Bank https://www.worldbank.org/en/topic/ financialinclusion/publication/digita....

Mehta S, Patel K., \& Mehta K. (2016). Demonetisation: shifting gears from physical cash to digital cash. Working papers (No. 2016-12-14) from Voice of Research. http://EconPapers.repec.org/RePEc:vor:issues.

Mukhopadhyay, B. (2016). Understanding cashless payments in India, financial innovation. ISSN 2199-4730, Springer, Heidelberg, 2(27), 1-26, http:/ /dx.doi.org/10.1186/s40854-016-0047-4.

Narayan, P. (2005). The saving and investment nexus for China: evidence from cointegration tests. Applied Economics, 37(17), 1979-1990.

Ozili P. K. (2018). Impact of digital finance on financial inclusion and stability, Borsa Istanbul Review, 18(4), 329340.

Panagariya A. (2019). Digital revolution, financial infrastructure and entrepreneurship: the case of India. Working Paper No. 2019-01 School of International and Public Affairs Columbia University New York.

Pesaran, M. H., \& Shin, Y. (1995). An Autoregressive distributed lag modelling approach to cointegration analysis. DAE Working Paper Series No 9514, Department of Applied Economics, University of Cambridge, England.

Pesaran, M. H., Shin, Y., \& Smith, R. J. (2001). Bounds testing approaches to the analysis of level relationships. Journal of Applied Econometrics, 16, 289-326.

Raichoudhury, A. (2020). Major Determinants of financial inclusion: state-level evidences from India. Vision. 24(2), 151-159.

Reserve Bank of India (Annual Report), August 25, (2020). Government of India, New Delhi.

Shin, Y., Kwiatkowski, D., Schmidt, P., \& Phillips, P. C. B. (1992). Testing the Null Hypothesis of Stationarity Against the Alternative of a Unit Root: How Sure Are We That Economic Time Series Are Nonstationary? Journal of Econometrics, 54(1-3), 159-178.

Sikdar, P., \& Kumar, A. (2017). Payment Bank: a catalyst for financial inclusion. Asia-Pacific Journal of Management. $12(3 \& 4), 226-231$.

Singh, R., \& Malik, G. (2019). Impact of digitalization on Indian rural banking customer: with reference to payment systems. Emerging Economy Studies. 5(1), 31-41.

Stavins, J. (2001). Effect of consumer characteristics on the use of payment instruments. New England Economic Review, 3, 19-31.

Steurer, R., Langer, M. E., Konrad, A., \& Martinuzzi, A. (2005). Corporations, stakeholders and sustainable development: A theoretical exploration of business-society relations. Journal of Business Ethics, 61, 263-281.

Stock, J. H., \& Mark W. W.. (1993). A simple estimator of cointegrating vectors in higher order integrated systems. Econometrica, 61(4), 783-820.

World Bank. (2014). Digital finance: Empowering the poor via new technologies. Available at: http:// www.worldbank.org/en/news/feature/2014/04/10/digital-finance-empowering-poor-new-technologies. 